\title{
Study of periodic vertical crustal movement in the Omaezaki peninsula, Central Japan, and it's tectonic implications
}

\author{
Gamal El-Fiky* and Teruyuki Kato \\ Earthquake Research Institute, Tokyo University, Tokyo 113-0032, Japan \\ (Received July 8, 1999; Revised September 22, 1999; Accepted October 29, 1999)
}

\begin{abstract}
As a part of the earthquake prediction project in the Tokai district, levelling observations are being carried out four times a year in the Omaezaki peninsula. To analyze this time dependent data, an adjustment method in which the velocity of vertical motions, the amplitude and phase of annual variation of each benchmark are assumed to be unknown is applied. The main results of the analysis are summarized as follows: (1) at reference time 1981.0, the average phase of benchmarks along the levelling route between Kakegawa city and Omaezaki is about 21 degree, (2) at BM140-1 (Kakegawa), relative to BM92305 (Omaezaki) the maximum amplitude of one-year period variation is about $7.55 \mathrm{~mm}$, i.e., the difference between the top and bottom of wave movement may reach $15.1 \mathrm{~mm}$, and (3) the subsidence rate on the levelling route from BM140-1 to BM92305 decreases gradually as the benchmark is farther from the fixed point BM92305 with the maximum subsiding rate of 7.7 $\mathrm{mm} / \mathrm{yr}$.

The estimated rates of vertical deformation (i.e., after removing the seasonal variation) are inverted to estimate interplate coupling between the subducting Philippine Sea plate and the overriding continental plate. This facilitates understanding of the strain accumulation process in this complicated region. The results indicate that there is a high coupled region extending from 7 to $27 \mathrm{~km}$ deep, the maximum back-slip rate in this region reaches $27 \mathrm{~mm} / \mathrm{yr}$, and the direction of the plate convergence at the Suruga Trough is $\mathrm{N} 54^{\circ} \mathrm{W} \pm 5^{\circ}$.
\end{abstract}

\section{Introduction}

The Tokai district, central Japan, is subjected to interaction of two plates, the Philippine Sea plate and the Eurasian or Amurian plate (Fig. 1). The Philippine Sea plate is subducting beneath the continental Eurasian plate in the NW direction with a low angle at the Suruga Trough (Seno, 1977; Minster and Jordan, 1979).

Historical documents show that the large interplate earthquakes have repeatedly occurred along the Nankai trough with an average interval of about $120 \mathrm{yr}$ (Utsu, 1974). The recent events, which occurred in the Tokai and Kinki districts, are the 1707 Hoei (M8.4), 1854 Ansei (M8.4), and 1944 Tonankai (M8.0) earthquakes. On the basis of the distributions of seismic intensity, co-seismic crustal movements, and the running height of excited tsunami waves, Ishibashi $(1977,1981)$ concluded that the Suruga Bay area (Fig. 1) is as a seismic gap, where tectonic stress that can generate a large interplate earthquake has been accumulated since the 1854 earthquake. To detect premonitory phenomena of the impending "Tokai earthquake" various kinds of observations, such as seismic activity, crustal movement,

*Currently on leave from National Research Institute of Astronomy and Geophysics, Helwan, Egypt.

Copy right $\odot$ The Society of Geomagnetism and Earth, Planetary and Space Sciences (SGEPSS); The Seismological Society of Japan; The Volcanological Society of Japan; The Geodetic Society of Japan; The Japanese Society for Planetary Sciences. electrical resistively, and hydrological and geochemical changes, have been conducted.

As a part of the earthquake prediction program in the Tokai district, the Geographical Survey Institute (GSI) have performed levelling surveys repeatedly in the Omaezaki peninsula (Fig. 2). It has been observed that the peninsula is subsiding for the past 100 years (e.g., GSI, 1978). The subsidence is considered to be due to subduction of the Philippine Sea plate at the Suruga Trough. In 1974, seismic activity in adjacent area, Izu peninsula, increased suddenly with enhanced rate of subsidence at Omaezaki. This change in the mode of deformation drew wide attention (GSI, 1977). In order to monitor further development, levelling has been performed four times a year since 1981. This frequent repetition of levelling in Omaezaki indicates that there is obvious seasonal crustal motion (Fig. 3) in this area (e.g., Tanaka and Gomi, 1989; GSI, 1998). It raises the doubt that, for least-squares network adjustment, the velocity model in which rates of vertical movements are linear functions of time (El-Fiky et al., 1996; El-Fiky, 1998) is no longer valid.

This paper presents the analysis of the time dependent levelling observation data in the Omaezaki area using an adjustment method in which the velocity of vertical motions, the amplitude and phase of annual variation of each benchmark are assumed to be unknown in the leastsquares network adjustment. Then, the estimated rates of 
vertical deformation (i.e., after removing the seasonal variation from levelling data) are inverted to estimate interplate coupling between the subducting Philippine Sea plate and the overriding continental plate. In the present study, we apply the inversion technique developed by Yabuki and Matsu'ura (1992). This enables us to

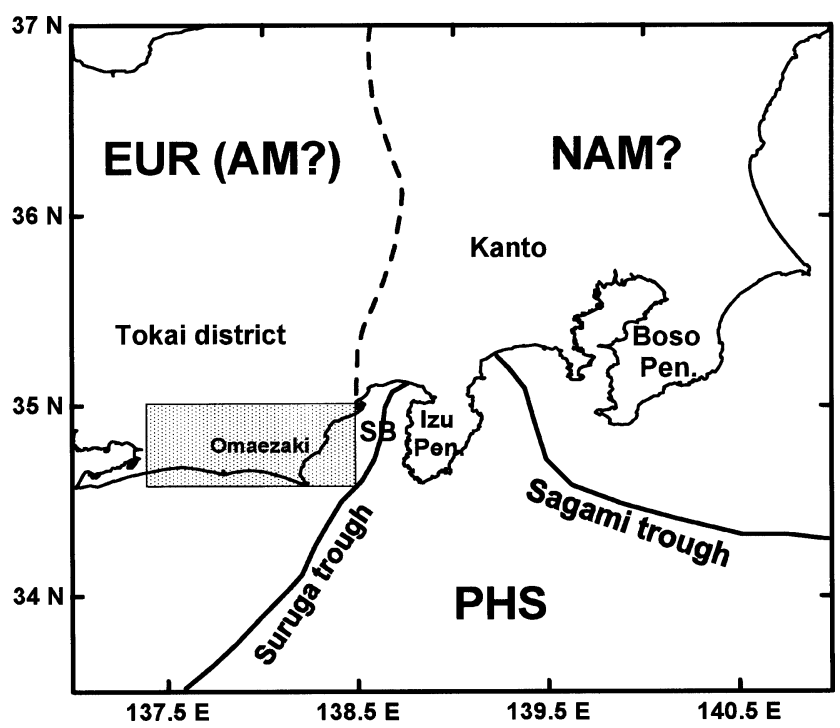

Fig. 1. Major plate boundaries in and near Tokai district and the studied region (shaded area). EUR, AM, NAM, and PHS are Eurasian, Amurian, North American, and Philippine Sea plates respectively. SB indicates the Suruga Bay. elucidate the spatial distribution of the strength and the direction of interplate coupling and to discuss the process of strain accumulation in this complicated region.

\section{Levelling Data in Omaezaki Area}

Levelling data employed here comprise first-order levelling measurement carried out by the GSI. The levelling routes are shown in Fig. 2. The levelling observations have been repeated four times a year along the route from BM140-1 to BM1354, twice a year along the route from BM1354 to the reference BM92305 at Omaezaki tidal station, and once a year along all other routes of the network shown in Fig. 2. We divided all the levelling data into two data sets: the first one includes routes from BM140-1 to BM1354 via BM2597 and from BM1354 to BM92305 on which twice or four times of levelling have been repeated every year, and the second consists of all other routes in Fig. 2 on which levelling has been done once every year. The levellings along the first route have been repeated approximately in January, April, July and October for the route from BM140-1 to BM1354 via BM2597, and in April and October for the route from BM1354 to BM92305 (GSI, 1998).

\section{Short Term Vertical Movement}

\subsection{Mathematical model}

The motion and annual variation of $i$-th benchmark at time $t, H_{i}^{t}$, can be described by the following equation:

$$
H_{i}^{t}=H_{i}^{0}+\Delta_{i}+R_{i} \delta t+A_{i} \cos \left(2 \pi(\delta t)-\theta_{i}\right)
$$

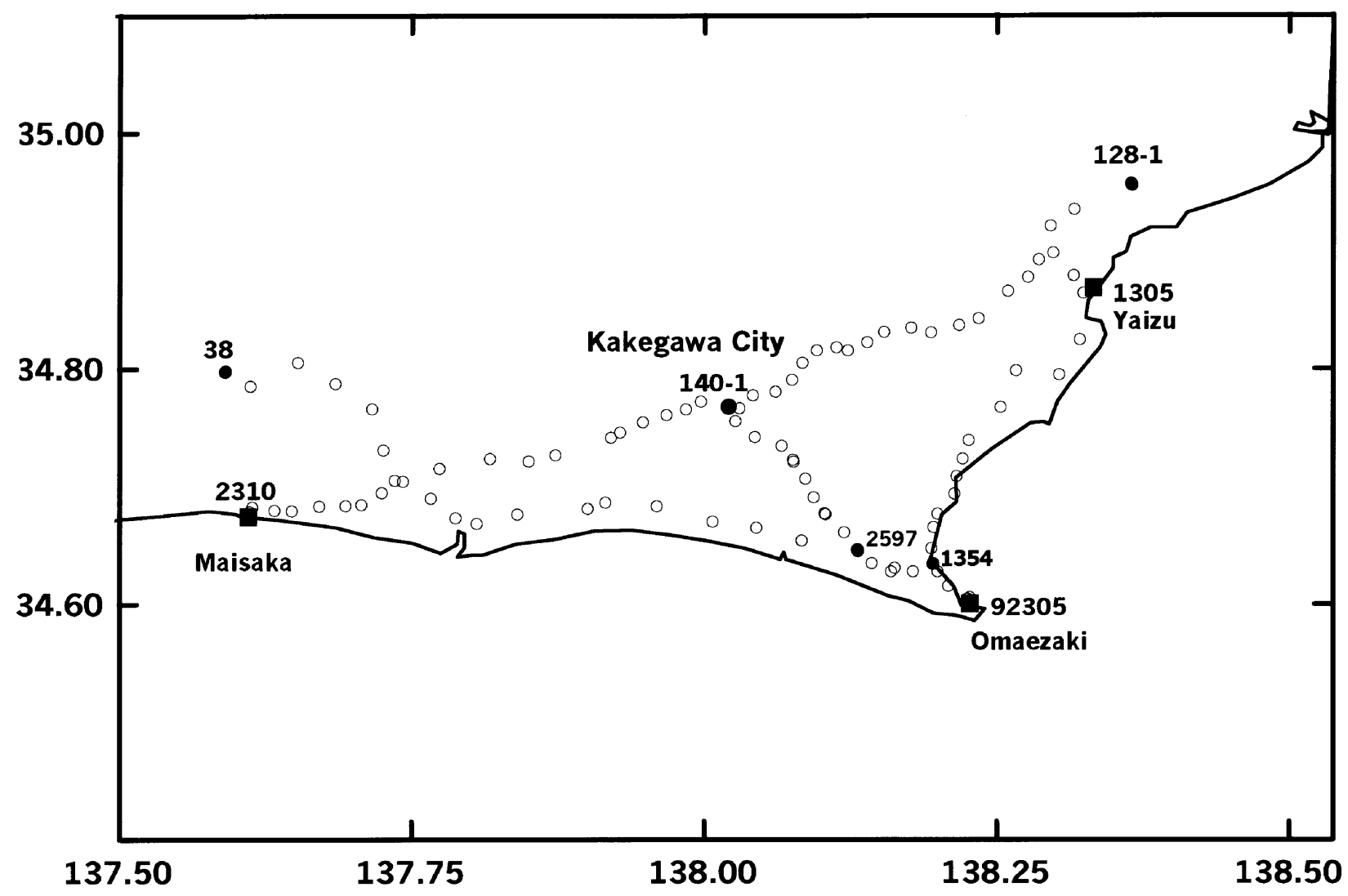

Fig. 2. Levelling network (open circle) and tidal stations (solid squares) in the Omaezaki peninsula. 
Fixed point is Kakegawa 140-1 Reference time is 1962

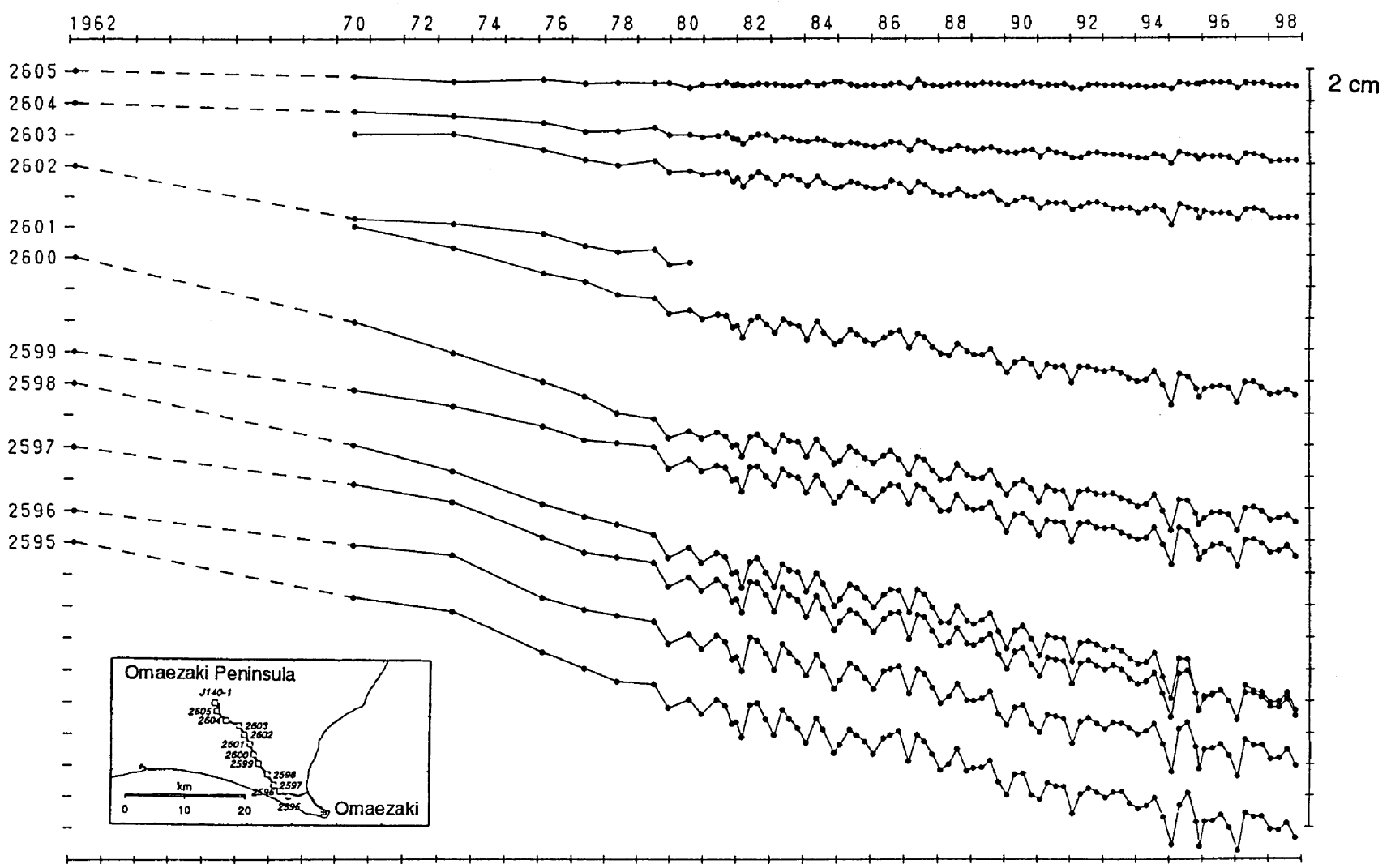

Fig. 3. Seasonal change in heights of benchmarks between Kakegawa and Omaezaki relative to BM140-1 in Kakegawa, from GSI (1999).

where $H_{i}^{0}$ is the approximate height of $i$-th benchmark at the reference time $t^{0}, \Delta_{i}$ is the correction to approximate height $H_{i}^{0}, R_{i}$ is the rate of vertical movement linear with time at $i$-th benchmark, $\delta t$ is the time difference between epoch $\mathrm{t}$ and reference epoch $t^{0}$, respectively. The first three terms on the right hand of Eq. (1) have been used as usual network adjustment with velocity model (e.g., ElFiky et al., 1996). In this study, we introduce the fourth term to represent the seasonal change, where $A_{i}$ is the amplitude of one-year variation, and $\theta_{i}$ is the phase of oneyear period variation at time $t^{0}$, respectively.

In levelling, approximate height $H_{i}^{0}$ is generally obtained from observed height differences and height of a starting benchmark. Precise levelling gives height differences $l_{i j}$, between benchmarks $i$ and $j$. Thus we obtain the error equation as follows:

$$
V_{i j}^{t}=H_{j}^{t}-H_{i}^{t}-l_{i j}{ }^{t},
$$

where $V_{i j}{ }^{t}$ is the residual of $l_{i j}{ }^{t}$, which is the observed height difference between benchmark $i$ and $j$ at time $t$. From Eqs. (1) and (2) we obtain the following equation:

$$
\begin{gathered}
V_{i j}^{t}=\Delta_{j}-\Delta_{i}+\left(R_{j}-R_{i}\right) \delta t+\left(\alpha_{j}-\alpha_{i}\right) \cos (2 \pi(\delta t)) \\
+\left(\beta_{j}-\beta_{i}\right) \sin (2 \pi(\delta t))+d_{i j}^{t},
\end{gathered}
$$

with

$$
\alpha_{i}=A_{i} \cos \left(\theta_{i}\right), \quad \alpha_{j}=A_{j} \cos \left(\theta_{j}\right)
$$

$$
\beta_{i}=A_{i} \sin \left(\theta_{i}\right), \quad \beta_{j}=A_{j} \sin \left(\theta_{j}\right),
$$

and

$$
d_{i j}^{t}=H_{j}^{0}-H_{i}^{0}-1_{i j}{ }^{t}
$$

Note that from the above equations the amplitude $A_{i}$ and phase parameters $\theta_{i}$ of the $i$-th benchmark are estimated by

$$
\begin{aligned}
& A_{i}=\left(\alpha_{i}^{2}+\beta_{i}^{2}\right)^{1 / 2} \\
& \theta_{i}=\tan ^{-1}\left(\beta_{i} / \alpha_{i}\right)
\end{aligned}
$$

respectively. Equation (3) leads to the following observation equation in matrix form:

$$
\boldsymbol{V}_{n}=\boldsymbol{A}_{n, m} \boldsymbol{X}_{m}+\boldsymbol{d}_{n}
$$

where $V_{n}$ is a residual vector when $n$ is the total number of observations, $\boldsymbol{A}_{n, m}$ is the coefficient matrix when $m$ is the number of parameters, $\boldsymbol{X}_{m}$ is the unknown parameter vector including $\Delta, R, \alpha$, and $\beta . d_{n}$ is a given constant vector. Least squares solution of Eq. (6) under the condition

$$
\boldsymbol{V}^{\boldsymbol{T}} \boldsymbol{P} \boldsymbol{V}=\text { minimum }
$$




$$
\hat{x}=\left(\boldsymbol{A}^{T} \boldsymbol{P} \boldsymbol{A}\right)^{-1} \boldsymbol{A}^{T} \boldsymbol{P d},
$$

where the upper index $\boldsymbol{T}$ indicates matrix transposition. $\hat{x}$ is the estimated parameters, $\boldsymbol{P}$ is the weight matrix, and the other parameters are as mentioned before. Here, we assume that $\boldsymbol{P}$ is inversely proportional to the distance between the adjacent benchmarks. The covariance matrix $\Sigma_{(X)}$ of the estimated parameters is

$$
\sum_{(X)}=\hat{\sigma}_{\mathrm{o}}^{2}\left(\boldsymbol{A}^{\boldsymbol{T}} \boldsymbol{P} \boldsymbol{A}\right)^{-1}
$$

$\hat{\sigma}_{\mathrm{o}}^{2}$ is the a posterior variance given by

$$
\hat{\sigma}_{\mathrm{o}}^{2}=\boldsymbol{V}^{\boldsymbol{T}} \boldsymbol{P} \boldsymbol{V} /(n-m),
$$

where $(n-m)$ is the degree of freedom when $n$ is the number of observations and $m$ is the rank of coefficient matrix $\boldsymbol{A}$.

\subsection{Results and discussions}

As is shown in Fig. 3, seasonal change is apparent in the levelling data (e.g., Nishi, 1985). If the levelling be carried out several times every year on randomly distributed dates, it would be possible to estimate the amplitude and phase of one-year period variation with high accuracy.

In order to obtain the absolute vertical rates at all benchmarks, we link levelling data with tidal records. Kato and Tsumura (1979) have developed a method to evaluate absolute crustal movements from tidal records. Using this method, the average uplift rates over the period from 1981 to 1995 at Maisaka, Omaezaki and Yaizu tidal stations are estimated to be $3.8 \pm 0.6,-7.0 \pm 0.5$, and $-6.9 \pm 0.7 \mathrm{~mm} / \mathrm{yr}$, respectively. The linear rate of Omeazaki station was used as a known value for adjustment of the levelling network, because this station has long history and high accuracy.

Using the above method, least-squares adjustment was performed to all data of the whole network in Fig. 2 for the period from 1981 to 1995 . The estimated velocities, amplitudes and phases at benchmarks along the levelling route from BM140-1 (Kakegawa city) to the reference BM92305 (Omaezaki tidal station) are listed in Table 1. The largest standard deviation of estimated velocity along the levelling route is only $0.18 \mathrm{~mm} / \mathrm{yr}$ (Table 1). Even though the levelling data are collected only four times every year, the amplitude and phase are well estimated with their average standard deviations being about 0.85 $\mathrm{mm}$ and 14.2 degree, respectively. That is to say, the phase of one-year period variation can be determined at an accuracy of about 14.4 days. The unstable determination of phases at benchmarks BM82305, and BM2593-1 (Fig. 6) is due to the assumption that there is no seasonal variation at BM92305 (tidal station at Omaezaki). This assumption restricts amplitudes of benchmarks close to the reference point to small values that may be caused the high uncertainty of phases there. However, these abnormal phase estimations have no physical meaning and should be ignored. The phases of most benchmarks at reference
Table 1. Estimated velocities of vertical movement, amplitudes and phases of one-year period, and their standard deviation at the benchmarks along the levelling route from Kakegawa city to Omeazaki.

\begin{tabular}{lccc}
\hline BM No. & $\begin{array}{c}\text { Velocity } \pm \text { SD } \\
(\mathrm{mm} / \mathrm{yr})\end{array}$ & $\begin{array}{c}\text { Amplitude } \pm \text { SD } \\
(\mathrm{mm})\end{array}$ & $\begin{array}{c}\text { Phase } \pm \text { SD } \\
(\text { degree })\end{array}$ \\
\hline $140-1$ & $-0.65 \pm 0.18$ & $7.55 \pm 1.08$ & $25.09 \pm 8.60$ \\
2130 & $-0.72 \pm 0.18$ & $7.51 \pm 1.06$ & $21.93 \pm 8.18$ \\
2605 & $-0.77 \pm 0.18$ & $7.47 \pm 1.06$ & $24.01 \pm 8.66$ \\
2604 & $-1.73 \pm 0.17$ & $6.32 \pm 1.04$ & $20.88 \pm 10.18$ \\
2603 & $-2.57 \pm 0.17$ & $5.37 \pm 1.01$ & $19.20 \pm 11.9$ \\
2129 & $-2.63 \pm 0.17$ & $4.78 \pm 1.00$ & $19.60 \pm 13.35$ \\
$2602-1$ & $-3.41 \pm 0.16$ & $4.63 \pm 1.00$ & $18.85 \pm 13.74$ \\
2601 & $-3.80 \pm 0.16$ & $3.75 \pm 0.98$ & $18.30 \pm 16.9$ \\
2600 & $-4.20 \pm 0.15$ & $3.14 \pm 0.97$ & $19.15 \pm 20.14$ \\
2599 & $-4.14 \pm 0.15$ & $2.84 \pm 0.96$ & $19.21 \pm 22.17$ \\
2128 & $-4.35 \pm 0.15$ & $2.71 \pm 0.96$ & $19.72 \pm 23.28$ \\
2598 & $-5.70 \pm 0.14$ & $1.98 \pm 0.78$ & $7.00 \pm 21.88$ \\
2597 & $-5.40 \pm 0.13$ & $1.58 \pm 0.83$ & $8.48 \pm 17.59$ \\
2596 & $-5.23 \pm 0.13$ & $1.24 \pm 0.88$ & $15.87 \pm 19.25$ \\
2595 & $-6.27 \pm 0.12$ & $1.46 \pm 0.80$ & $9.26 \pm 21.3$ \\
1356 & $-6.18 \pm 0.12$ & $1.76 \pm 0.82$ & $12.85 \pm 28.79$ \\
2594 & $-6.52 \pm 0.11$ & $0.85 \pm 0.59$ & $28.77 \pm 22.14$ \\
1354 & $-6.31 \pm 0.1$ & $0.76 \pm 0.48$ & $31.51 \pm 17.59$ \\
10149 & $-7.7 \pm 0.08$ & $1.43 \pm 0.87$ & $40.32 \pm 21.25$ \\
$2593-1$ & $-7.38 \pm 0.06$ & $0.93 \pm 0.59$ & $32.12 \pm 50.73$ \\
82305 & $-7.18 \pm 0.02$ & $0.38 \pm 0.26$ & $63.19 \pm 53.35$ \\
92305 & $-7.00 \pm 0.85$ & $0.00 \pm 0.00$ & $0.00 \pm 0.00$ \\
\hline & & &
\end{tabular}

time 1981.0 vary around 21 degree, most of them confined in the range 18 32 degree. On the other hand, there is a trend that the phase of benchmarks near the reference point at Omaezaki is larger and that near BM140-1 (the most inland point) is smaller (Table 1).

The estimated velocities $R_{i}$, amplitudes $A_{i}$ and phases $\theta_{i}$ at reference time 1981.0 are also illustrated in Figs. 4, 5, and 6 by solid circles respectively. The bars shown in these figures indicate the standard deviation. It can be clearly seen from Fig. 4 that the subsiding rate decreases gradually as the benchmark is farther from the fixed point BM92305 at Omeazaki. On the contrary, the amplitude increases gradually as the benchmark goes farther from the fixed point (Fig. 5). It is an important fact that the maximum amplitude at the BM140-1 (the most inland point) is as large as $7.55 \mathrm{~mm}$, about equal to the maximum subsiding rate of $7.7 \mathrm{~mm} / \mathrm{yr}$ along the levelling route (Table 1). That is to say, the difference between the top and bottom of undulation may reach $15.1 \mathrm{~mm}$. This raises a serious question if the method of estimating vertical rates by comparing two epochs of levelling data without correcting seasonal change, provides precise estimates or not (El-Fiky et al., 1996).

Concerning the origin of the above seasonal variation, there are several natural phenomena that have annual periodicity and we discussed some major important factors among them. The first possible cause is the atmospheric refraction. The Omaezaki peninsula is known for its flat top named Makinohara plain that (see Fig. 12) is a dissected fan formed about 100,000 BP (Tajima et al., 1984). So, the refraction effect is a serious problem. However, the daytime change in refraction effect is much larger than the seasonal variation and the elevation change is too much periodic to 
Benchmark No.

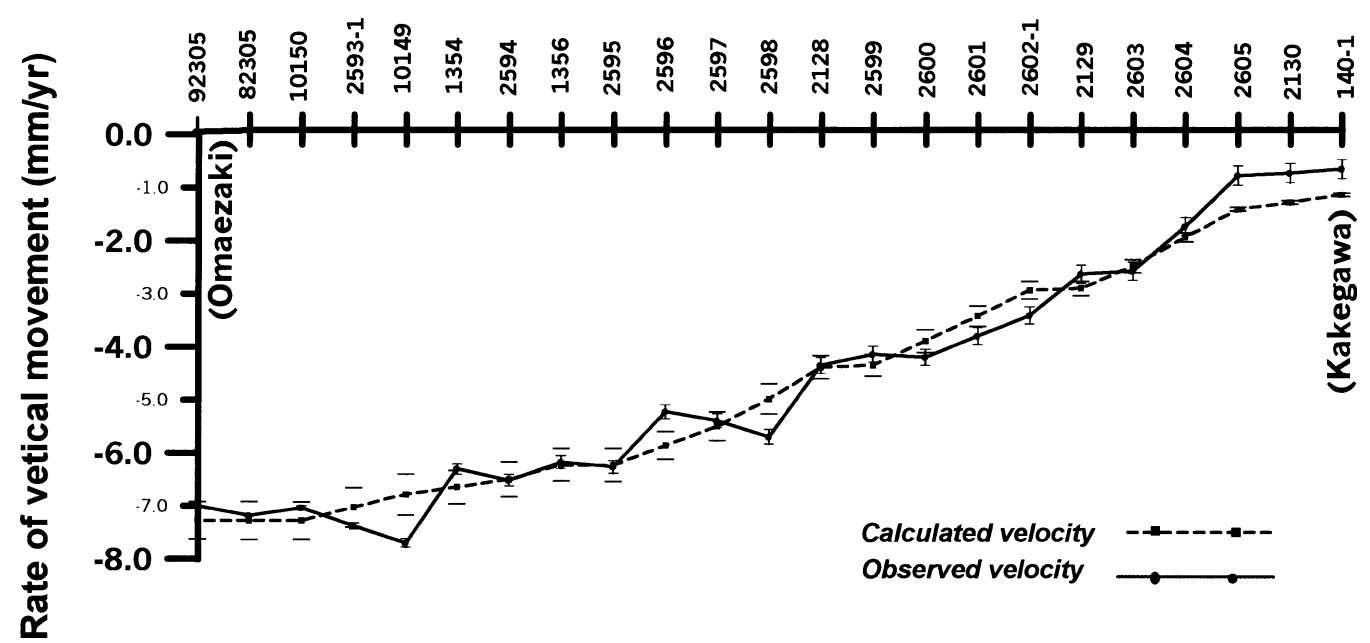

Fig. 4. Adjusted rate of vertical movement (sold line) and its standard deviation along the levelling route from BM92305 (Omaezaki) to BM1401 (Kakegawa city) based on the rate of vertical movement of Omaezaki tidal station. The dashed line is the calculated rate from back-slip model. Unit is $\mathrm{mm} / \mathrm{yr}$.

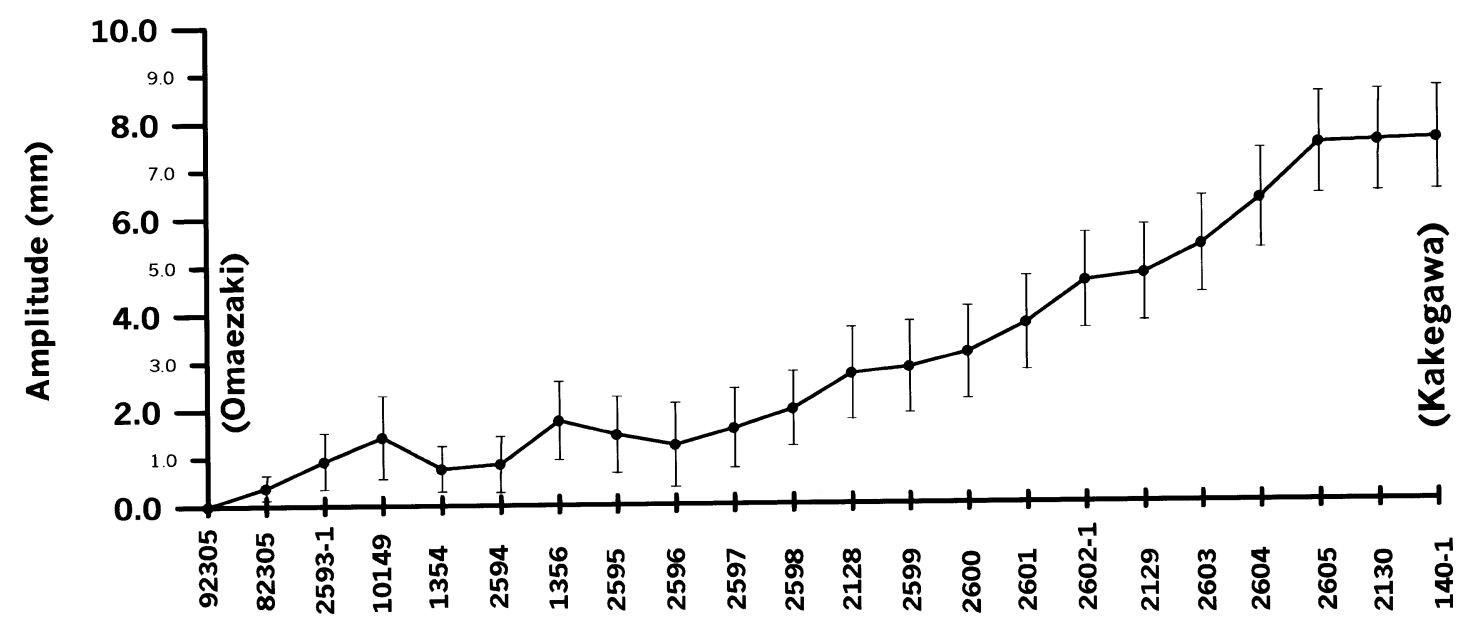

Benchmark No.

Fig. 5. Distribution of seasonal variation amplitude and its standard deviation along levelling route from MB92305 (Omaezaki) to BM140-1 (Kakegawa city). Unit of amplitude is $\mathrm{mm}$.

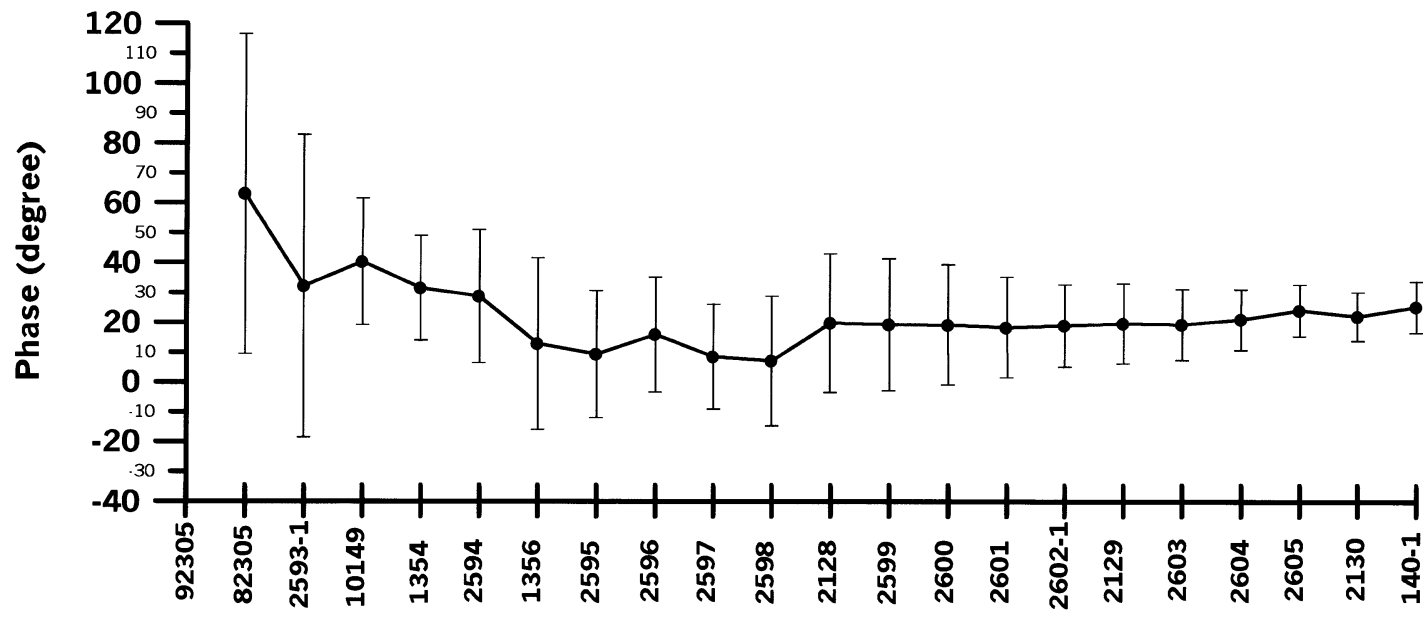

Benchmark No.

Fig. 6. Distribution of seasonal variation phase and its standard deviation along the levelling route from BM92305 (Omaezaki) to BM140-1 (Kakegawa city). Unit of phase is degree. 
be the result of the refraction effect. On the other hand, rod calibration error is negligible because the height difference between Omaezaki and Kakegawa is relatively small.

Another possible cause for annual change is the annual term of the earth tide. The maximum range of actually observed tidal tilt is about 0.017 arc (Vanicek and Krakiwsky, 1982). Since the levelling route (distance) between Kakegawa and Omaezaki is about $25 \mathrm{~km}$, the maximum possible vertical motion of Kakegawa relative to Omaezaki does not exceed $2 \mathrm{~mm}$. So, this cannot be considered as an important factor. It is well known that some clay minerals such as Montmorillonite swell in water. So, if rainfall varies seasonally, elevation may change annually. However, the average amount of rainfall in the area does not have such a large horizontal gradient. In addition, the rainfall is not sinusoidal; so this also cannot be considered as one of the important factors. The remaining factors are tidal loading, ocean tide, ground water, and tidal level.

Several models have been proposed to study the above factors for the periodical variation in the vertical movements of the Omaezaki peninsula. Tanaka (1981) presented a tidal loading model to explain the phase difference of about 2-3 month's delay of elevation change from tidal change, but it was not able to offset the amplitude. Tajima et al. (1984) proposed elastic buoyancy deformation model to explain both the phase and amplitude. They analyzed elevation data. However, the result was not consistent with the recent tidal phase as far as phase difference is concerned. On the other hand, ground water model could not produce the amplitude of this seasonal change (Tanaka and Gomi, 1989). Inouchi and Hosono (1987) found strong correlation between the phase changes of elevation and tidal level during daytime. They pointed out that it is due to the difference between the daytime (10 AM to 4 PM) survey values and all day mean values of tidal level. However, a little difference is still observed from their phase comparison between changes in height of BM2595 and day time mean sea level at Omaezaki tidal station, and another important problem on output of the large amplitude has yet been left unsolved. Tanaka and Gomi (1989) made a comparison among the phase change of crustal movements in the Omaezaki Promontory, the Miura Peninsula, and the Boso Peninsula. Their investigations indicate that the phases of seasonal variation in the Miura and Boso Peninsulas are curiously different from the phase in the Omaezaki Promontory.

Probably most or all of these factors contribute to the seasonal change in the levelling data. It is, however, difficult to evaluate quantitatively the relative importance between these factors.

Finally, we compile a contour map (Fig. 7) for the distribution rates of vertical crustal movements of the Omaezaki peninsula for the interval 1981 to 1995 . The estimated phases and amplitudes along the levelling routes that were observed more than once a year are removed from the vertical rates in this figure. The velocity distribution in Fig. 7 clearly shows that contour lines of subsidence in the Omaezaki area are approximately parallel to the Suruga Trough, suggesting that the direction of

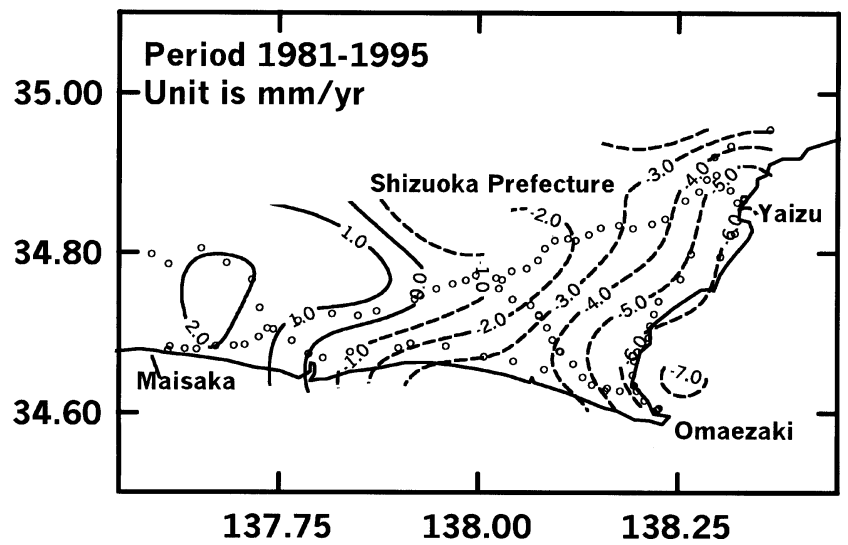

Fig. 7. Contour map of vertical crustal movement rate in the Omaezaki peninsula based on the rate of vertical movement of Omaezaki tidal station for period from 1981 to 1995 . Unit is $\mathrm{mm} / \mathrm{yr}$.

maximum tilt is approximately parallel to the direction of the movement of the Izu block relative to the Eurasian plate. This means that the vertical deformation in the Omaezaki area is due to the subduction along the Suruga Trough. In the next section, we try to estimate the interplate coupling between the subducting Philippine Sea plate and the overlying continental plate from these levelling data.

\section{The Inversion Analysis}

It is widely accepted that the degree of interplate coupling varies with depth in the contact zone along a plate boundary surface (Ruff and Kanamori, 1983; Peterson and Seno, 1984). Following Savage (1983), we consider that the subducting oceanic plate and the overlying continental plate are coupled at an intermediate depth and decoupled at the shallower or deeper parts of the plate boundary. In this study, we estimate the surface deformation on the continental plate only by imposing a normal dislocation source at the coupling interface. The amplitude of the dislocation is a measure of plate coupling when compared with total relative plate motion at this boundary. Estimation of such normal faulting by inverting surface displacement is what we call "back-slip inversion" (e.g., Sagiya, 1995; El-Fiky and Kato, 1999).

We employ the inversion technique developed by Yabuki and Matsu' ura (1992) to estimate the spatial distribution of back-slip from levelling data. Firstly we determine the geometry of the plate boundary (model fault surface) from the information of microearthquake distributions. Given the geometry of the model fault surface we can represent the distribution of back-slip by linear combination of basis functions (bi-cubic B-splines) defined on the model surface. Then, the problem is to find the best estimates of model parameters and reconstruct the back-slip distribution on the model fault surface.

In addition, we have another sort of information about the back-slip distribution; that is, the spatial variation of back-slip must be smooth to some degree because of the finiteness of stress accumulation in the locked region. In order to incorporate this information into the inversion, we introduce a measure of the roughness of the back-slip 


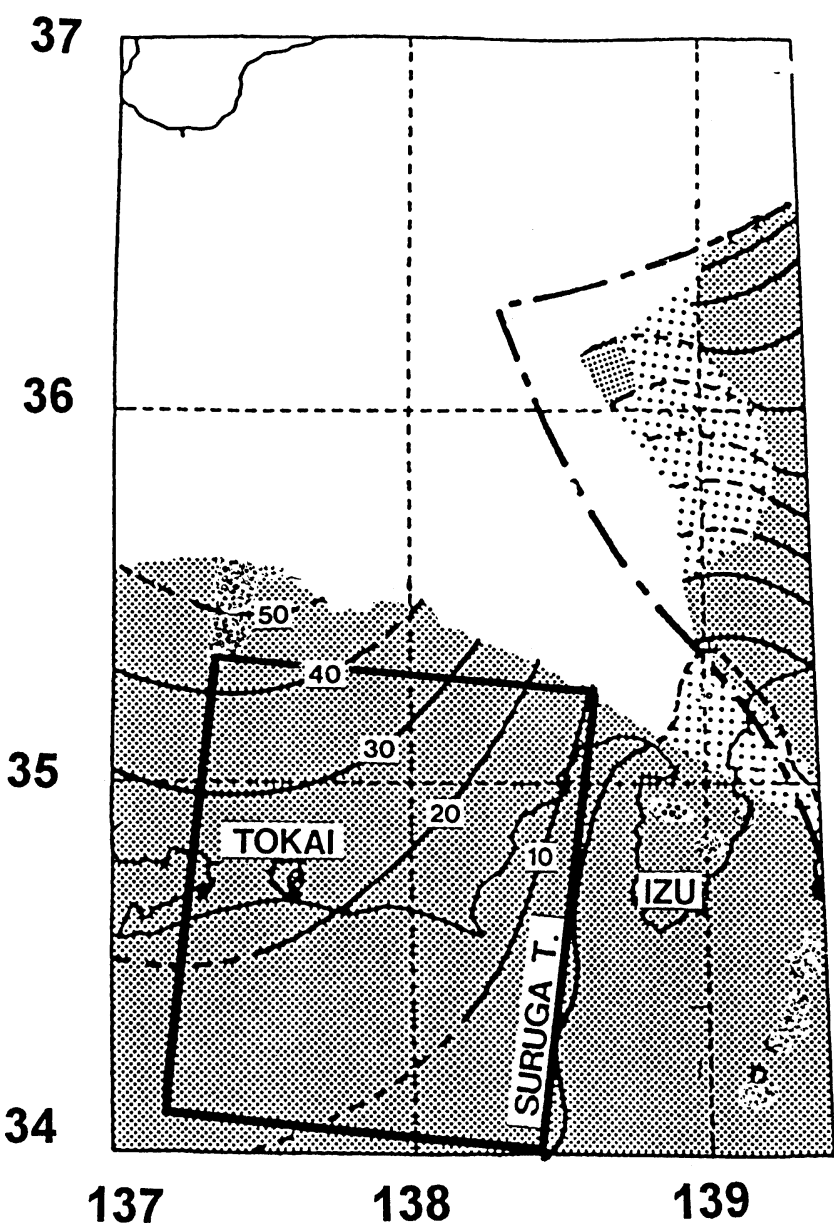

Fig. 8. Iso-depth contours (in $\mathrm{km}$ ) of the upper boundary of the Philippine Sea plate (Ishida, 1992). The rectangle indicates the model source region.

distribution. This prior information is represented in a form of probability density function (PDF) of the model parameters using an unknown parameter, which controls the strength of the prior constraints on the model parameters.

We define a likelihood function of the model parameters for given data. Then, we combine the prior PDF of the prior information with the likelihood function of the observed data based on Bayes' theorem. After that, we construct a posterior PDF of the model parameters, which is called a Bayesian model. The Bayesian model has flexibility in the selection of the relative weight of the two sorts of information. Then, the fundamental problem is to find the best estimation of relative weight and the model parameters from observed data. For the determination of the optimal values of the relative weight, we use Akaike's Bayesian Information Criterion (ABIC) proposed by Akaike $(1977,1980)$. Once the optimal values of relative weight are given, the best estimation of model parameters and the covariance of estimation errors can be obtained by using the algorithm of Jackson and Matsu'ura (1985).

The model source region and iso-depth contours of the upper boundary of the Philippine Sea plate, which has been obtained from the distribution of micro-earthquakes by Ishida (1992), are shown in Fig. 8. The eastern rim of the model source region is taken along the strike of the Suruga Trough.

We divide the model source region into $13 \times 11$ subsections and distribute $10 \times 8$ bi-cubic B-spline so that they homogeneously cover the whole region; the distribution of each component of back-slip on the model is represented by the superposition of $10 \times 8$ bi-cubic $\mathrm{B}$ spline with various amplitudes. Then our problem is to estimate the two hyperparameters that represent the relative weight between the prior information and the observed data as well as $160(=2 \times 10 \times 8)$ model parameters from the observed crustal deformation data (Fig. 7). This is equivalent to estimating the spatial distribution of backslip vectors on the model surface. We used the rates of vertical movements at 145 observed benchmarks after we removed the seasonal variation at levelling benchmarks that were observed more than once a year. The ratio of the above two hyperparameters is estimated to be 0.029 , which is relatively very small. This demonstrates that the model parameters are mainly constrained by the observed data and not by the a priori constraints.

\section{Results and Discussions of Back-Slip}

Figure 9 shows the distribution of the back-slip motion of the overlying continental plate relative to the subducting oceanic plate, inverted from the rates of vertical crustal movement (Fig. 7) for the period (1981-1995). The areas with estimated errors larger than the estimated back-slip rates are shadowed. The maximum back-slip rate of about $27 \mathrm{~mm} / \mathrm{yr}$ is identified beneath the coast line at Omeazaki. Back-slip decreases downward gradually on the plate boundary. Back-slip rate reduces to about $10 \mathrm{~mm} / \mathrm{yr}$ at a depth of about $27 \mathrm{~km}$. Direction of back-slip is $\mathrm{N} 54^{\circ} \mathrm{W} \pm$ $5^{\circ}$ on average over the region with back-slip rates greater than $15 \mathrm{~mm} / \mathrm{yr}$ which is consistent with the relative plate motion estimated using both seismological data $\left(\mathrm{N} 49^{\circ} \mathrm{W}\right.$ according to Seno et al., 1993) and GPS data (N45. $5^{\circ} \mathrm{W}$ according to Kotake et al., 1998). The strongly coupled region extends from $7 \mathrm{~km}$ to $27 \mathrm{~km}$ in depth. Considering the rate of relative plate motion to be $34 \mathrm{~mm} / \mathrm{yr}$ (Seno, 1977; Seno et al., 1993), we can say that about $80 \%$ of slip rate along the Suruga Trough is due to seismic coupling. The strength of coupling tends to decrease toward the shallower and deeper portions. Strain accumulation in the continental plate may be due to the plate interaction, which occurs in the part shallower than $27 \mathrm{~km}$ of the Omaezaki peninsula. The deeper part of the plate interface may move more smoothly and would not cause accumulation of seismogenic strain.

Assuming that the back-slip rate has been constant in time since the 1854 Ansei earthquake, we can roughly estimate the total moment accumulated during the last 145 years. In general the seismic moment $M_{\mathrm{o}}$ is defined by:

$$
M_{\mathrm{o}}=\mu D A_{\mathrm{s}}
$$

where $\mu$ is the rigidity of the medium, $D$ is the average fault slip, and $A_{\mathrm{s}}$ is the source area. $M_{\mathrm{o}}$ is estimated using the values of $\mu=3.4 \times 10^{10} \mathrm{~N} / \mathrm{m}^{2}, D=21(\mathrm{~mm} / \mathrm{yr}) \times 145(\mathrm{yr})$ $=3.04 \mathrm{~m}$, and $A_{\mathrm{s}}=5.03 \times 10^{9} \mathrm{~m}^{2}$. Here, for the evaluation 


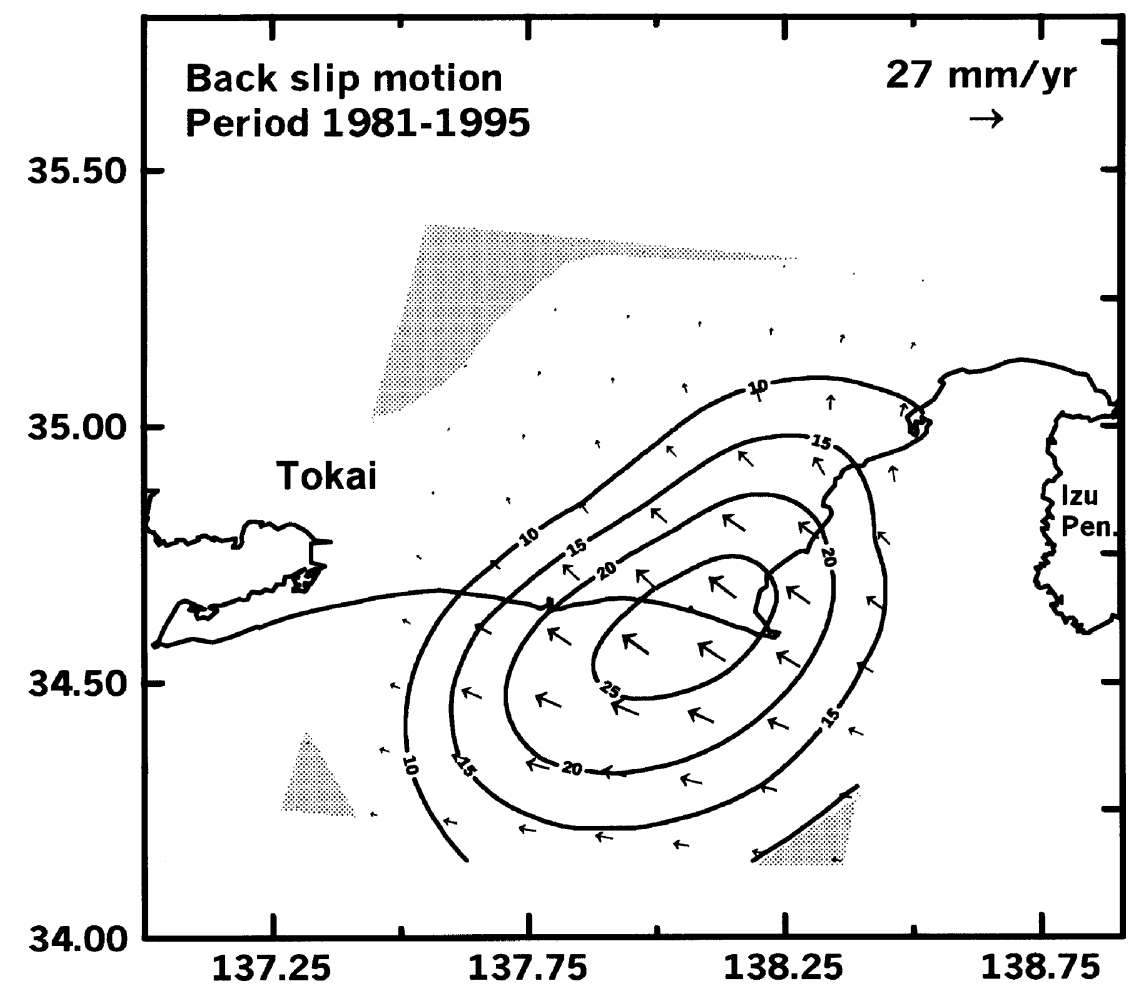

Fig. 9. The back-slip vectors of the overlying continental plate relative to the subducting plate, inverted from rates of vertical movement (Fig. 7) for the period from 1981 to 1995 . The areas with standard deviation larger than the estimated back-slip rates are shaded.

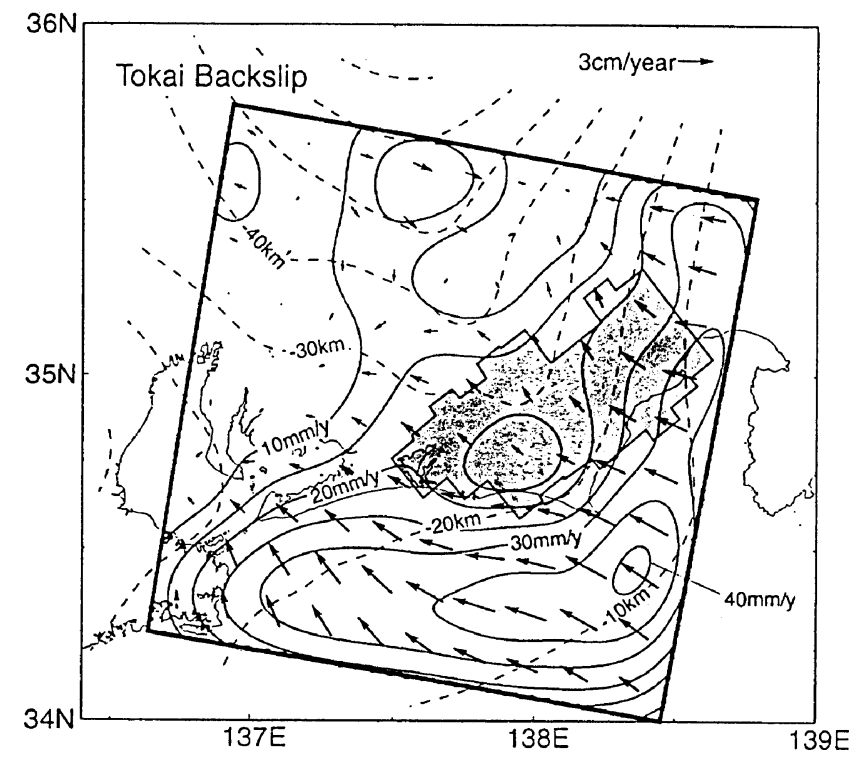

Fig. 10. Distribution of the back-slip estimated by Sagiya (1999). Arrows and solid contours indicate both direction and magnitude of back-slip. Dashes lines represent depth contours of plate boundary configuration. Shaded area is Matsumura's (1997) locked zone estimated from seismicity data.

of $A$, we assume that the area with back-slip rates greater than $15 \mathrm{~mm} / \mathrm{yr}$ is the source area of the forthcoming Tokai earthquake. From Eq. (10) the total seismic moment accumulated in this area is about $5.21 \times 10^{20} \mathrm{~N} / \mathrm{m}$. Then, using empirical relation of Kanamori (1977), the expected magnitude $M_{\mathrm{w}}$ of the earthquake is estimated to be 7.7 .
Sagiya (1999) inverted three components of 75 GPS velocity data in the Tokai, which were extracted from the Japanese nationwide GPS network during the period from January 1997 to March 1999 to deduce the back-slip distribution in the Tokai district (Fig. 10). Although the inversion procedure of this study is almost the same as that of Sagiya (1999), the two results are somehow different. Maximum back-slip of Sagiya is about $35 \mathrm{~mm} /$ $\mathrm{yr}$ at the depth of about $13 \mathrm{~km}$ located under the Sea of Enshu while maximum value of this study is about $27 \mathrm{~mm} /$ yr at depth of about $21 \mathrm{~km}$ beneath coastline at Omeazaki. This means that our analysis gives deeper maximum backslip. Yoshioka et al. (1993) inverted trilateration (19771988) and levelling (1972-1977) data to deduce the backslip distribution in the Tokai district. Although the backslip distribution obtained in the present study was derived from the levelling data alone, it is in good agreement with their results deduced from levelling and horizontal surveys. This may be due their model was mainly constrained by levelling data and horizontal data were not recovered very well.

Figures 11 and 4 compare the observed and calculated vertical rates at the benchmarks. As is readily seen, they are fairly consistent. To see the goodness of the fit quantitatively, the $\%$ variability $=[1-\mathrm{RV} / \mathrm{TV}] \times 100$ is calculated and found to be $95 \%$. Here, RV is the residual variance and TV is the variance of the observation. However, Fig. 4 shows that the observed data are fluctuating around the estimated values along the levelling route between Kakegawa city and Omaezaki. This is eminent seen especially near the tip of the peninsula. There is significant offset in vertical rate between BM1354 


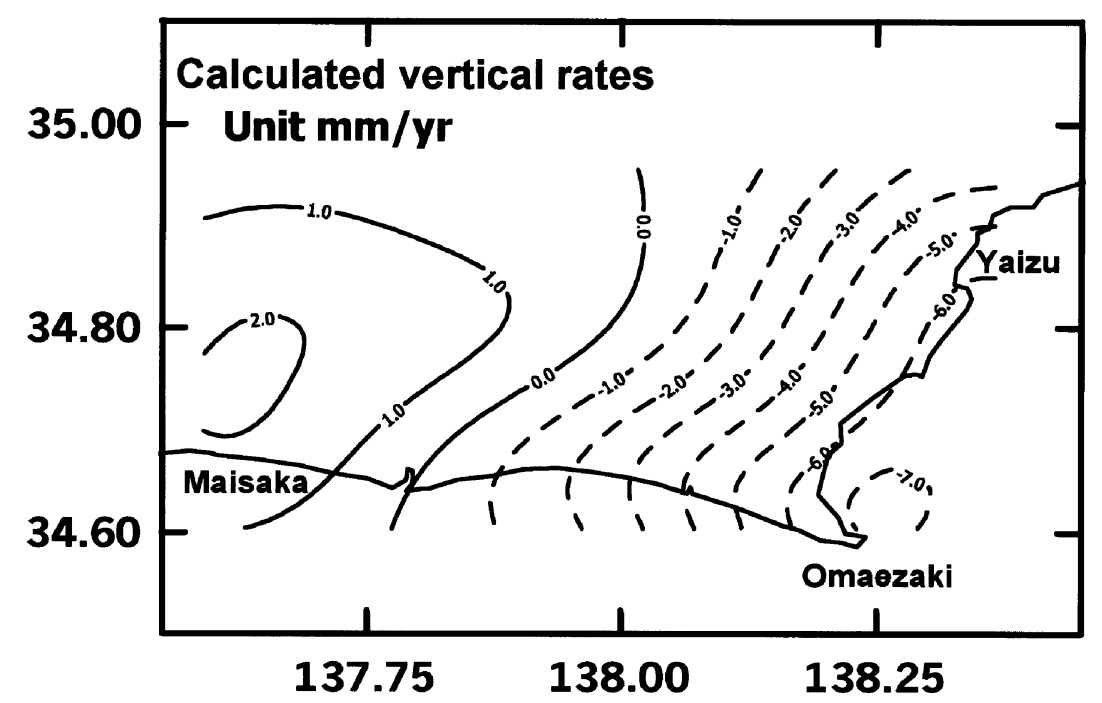

Fig. 11. Distribution of the vertical crustal movement rates calculated from the inverted back-slip distribution. Unit is mm/yr.

\section{$\square 1354$}

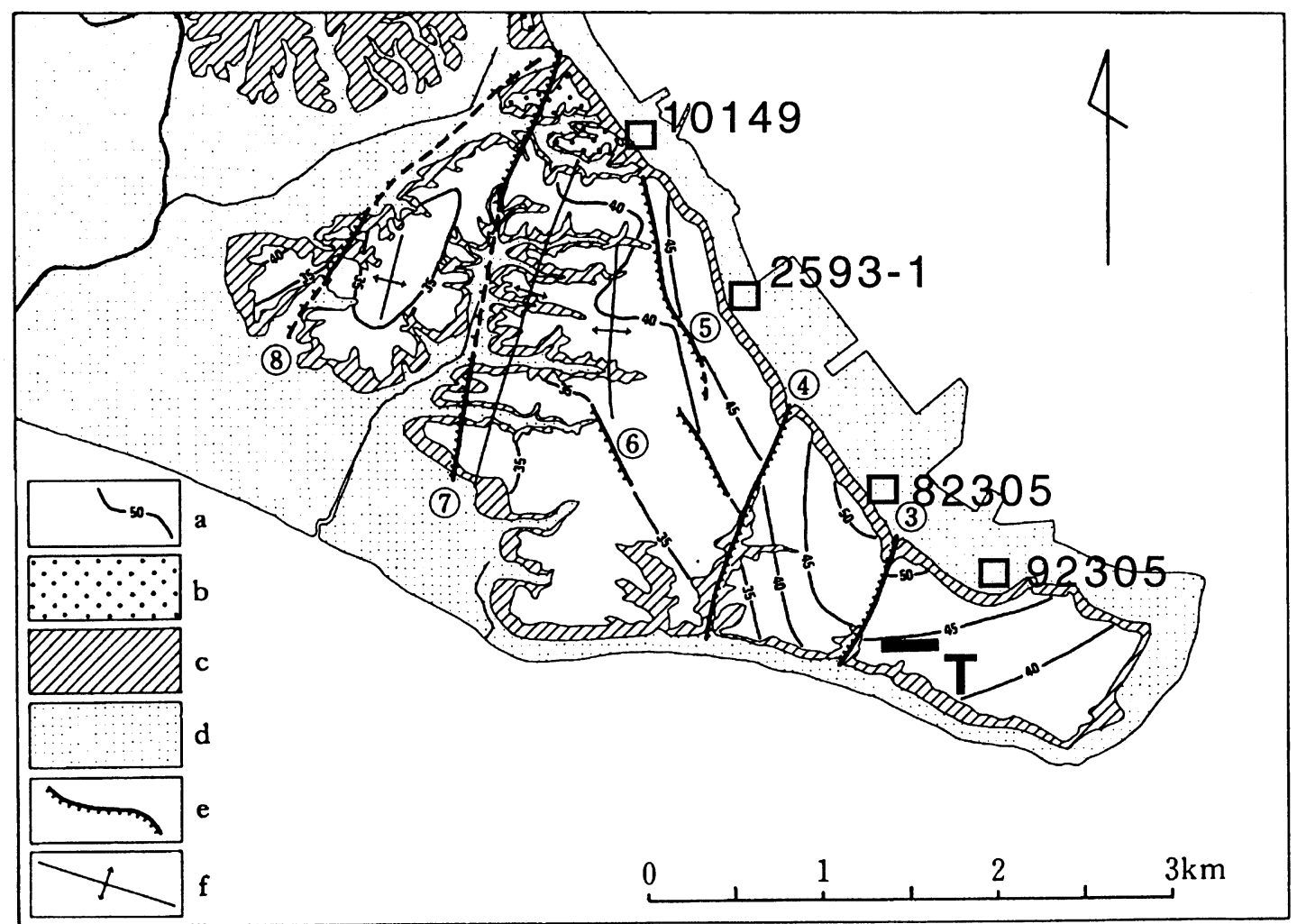

Fig. 12. Summit level nearby Omaezaki (original picture drawn by Masami Togo). a- Omaezaki level and its summit level heights, b- Jito-kata I level, c- slope, d- low land, e- active fault ((3) Serizawa fault, (4) Hirosawa fault, (5) Araya fault, (6) Nakahara fault, (7) Shiraha fault, (8) Shirahama fault), f- anticlinal buldge. Inset sqaures are the benchmark locations. The small bar with mark " $T$ " is the location and direction of long water-tube tilt meter of $328 \mathrm{~m}$. Locations are not very accurate. (figure modified from Active Faults in Japan-sheet maps and inventories_- The Research Group for Active Faults of Japan (1991), p. 211).

and BM10149. Also, the land block between BM10149 and BM92305 is inclining landward but not seaward, which is opposite from the calculated velocity. The landward tilt is consistent with long-distance water tube tilmeter that is operated by Geographical Survey Institute (e.g., GSI, 1999). Thus, local tilt observed at the tip of the peninsula may not be just an observational error. Figure 12 shows detailed geographical map at the tip of the peninsula (The Research Group for Active Faults of Japan, 1991). Added in the figure are benchmarks and the location of the tiltmeter. As is shown, there are some active faults that cut the levelling route. The offset shown 
in Fig. 4 indicates that there would be a block boundary at the Shiraha or Shirahama fault. This kind of local block motion was indicated earlier by a number of authors (e.g., Tsuboi, 1933; Scholz and Kato, 1978). Although more extensive surveys are clearly needed, the local inconsistency between observed and estimated vertical rate in Fig. 4 might partly be due to such local block motion.

Recently, Matsumura (1997) analyzed the seismicity pattern observed in the Tokai district in order to investigate the tectonic situation of the area west of Suruga Bay. In his analysis, directional variation in P-axes of microearthquakes in the subducted plate was interpreted by a coupling-decoupling transition on the plate interface. The coupling zone was located at a depth of 20-30 km landward. Compared with the area of large back-slip, Matsumura's coupling zone is slightly shifted landward compared with the present results.

Sagiya (1995) analyzed the geodetic deformation data to estimate the spatial distribution of interplate coupling in the Shikoku district, southwest Japan, where the Philippine Sea plate is subducting beneath the Eurasian plate along the Nankai trough for a seismic cycle. His results suggest that a strongly coupled region extends from 10 to $30 \mathrm{~km}$ depth and the maximum back-slip rate in the interseismic stage is $60 \mathrm{~mm} / \mathrm{yr}$ and the average direction of back-slip is ranging from $\mathrm{N} 30^{\circ} \mathrm{W}$ to $\mathrm{N} 70^{\circ} \mathrm{W}$. The depth extent of the coupled region is not significantly different between Tokai and Shikoku, but back-slip rate in Shikoku is about 2.2 times larger than of Tokai. This difference might be due to differences in relative plate motion. According to Seno et al. (1993), relative plate motion magnitude increases from Tokai to Shikoku along the Suruga-Nankai trough. Although Philippine Sea plate is subducting along the Suruga-Nankai trough, the northern tip of the plate, Izu peninsula, is colliding with the Japan island arc (e.g., Somerville, 1978) and plate subduction is not confirmed north of Izu from the seismicity (e.g., Ishida, 1992). Therefore, the motion of the Philippine Sea plate is considered to be decelerated or locked at the northern tip, and the relative plate motion is decreased at an adjacent Tokai area. Shikoku is located about $300 \mathrm{~km}$ west of Tokai area so that the relative plate motion in Shikoku is not so much affected by the collision of Izu peninsula. The average direction of back-slip in this study is about $\mathrm{N} 54^{\circ} \mathrm{W}$. This is roughly consistent with Seno et al. (1993) and Kotake et al. (1998). However, subduction at the Nankai trough is considered to be more representative motion of the Philippine Sea plate relative to the Eurasian plate than that of Tokai area because it is not influenced by the collision of Izu peninsula so much as mentioned above.

\section{Conclusions}

In the Omaezaki peninsula, seasonal crustal movement was observed by levelling data, which have been repeated four times every year since 1981. To understand the mechanism of this motion, a new levelling adjustment method has been applied in which the velocity of vertical motions, the amplitude and phase of annual variation of each benchmark are assumed to be unknown. The main results of the analysis by this method are summarized as follows: (1) The phases of most benchmarks along the levelling route between Kakegawa city and Omaezaki at reference time 1981.0 is about 21 degree. (2) The maximum amplitude of one-year period variation at BM140-1 at Kakegawa relative to BM92305 at Omaezaki reaches about $7.55 \mathrm{~mm}$. (3) The subsidence rate on the levelling route from BM140-1 at Kakegawa city to BM92305 at Omaezaki decreases gradually as the benchmark is farther from the fixed point BM92305 with maximum subsiding rate of $7.7 \mathrm{~mm} / \mathrm{yr}$.

Then, we removed the seasonal variation in the levelling data and carried out geodetic inversion analysis to find the spatial distribution of interplate coupling in the area. Significant results obtained here are: (1) there is a high coupled region extending from 7 to $27 \mathrm{~km}$ deep, (2) the maximum back-slip rate in this region reaches $27 \mathrm{~mm} / \mathrm{yr}$, (3) the direction of the plate convergence at the Suruga Trough is $\mathrm{N} 54^{\circ} \mathrm{W} \pm 5^{\circ}$, (4) the total seismic moment accumulated in the last 145 years in this area is estimated to be about $5.21 \times 10^{20} \mathrm{~N} / \mathrm{m}$ which corresponds to $M_{\mathrm{w}}=$ 7.7 .

Acknowledgments. We are grateful to the staff of the Geographical Survey Institute for providing the levelling data. We thank Dr. Tetsuichiro Yabuki for allowing us to use his source code for inversion analysis. We thank Dr. C. D. Reddy and Mr. Yosuke Aoki for their help and useful discussion. Comments of Dr. Thora Arnadottir, Dr. Takeshi Sagiya, and Prof. K. Heki were invaluable to improve the manuscript. The first author expresses sincere thanks to the Japan Society for the promotion of science (JSPS) for supporting him during this study.

\section{References}

Akaike, H., On entropy maximization principle, in Appl. Statis., edited by J. M. Krishnaiah, pp. 27-41, North-Holland, Amsterdam, 1977.

Akaike, H., Likelihood and the Bayes procedure, in Bayesian Statistics, edited by J. M. Bernardo, M. H. DeGroot, D. V. Lindley, and A. F. M. Smith, pp. 143-166, Univ. Press, Valencia, Spain, 1980.

El-Fiky, G. S., Temporal change of the crustal deformation and interplate coupling in the Tohoku district, northeast Japan-a New Approach-, Ph.D. Thesis, Fac. of Scien., Univ. of Tokyo, 190 pp., 1998.

El-Fiky, G. S. and T. Kato, Interplate coupling in the Tohoku district, Japan, deduced from geodetic data inversion, J. Geophys. Res., 104, 20361-20377, 1999.

EL-Fiky, G. S., T. Kato, and Y. Fujii, Vertical crustal movement in Tohoku district, Japan, deduced from dynamic adjustment of levelling and tidal data, Bull. Earthq. Res. Inst., Univ. of Tokyo, Japan, 71, 47$71,1996$.

Geographical Survey Institute of Japan, Crustal movements in the Tokai district, Rep. Cood. Comm. Earthq. Pred., 18, 75-80, 1977 (in Japanese).

Geographical Survey Institute of Japan, Crustal movements in the Tokai district, Rep. Cood. Comm. Earthq. Pred., 19, 96-99, 1978 (in Japanese).

Geographical Survey Institute of Japan, Crustal movements in the Tokai district, Rep. Cood. Comm. Earthq. Pred., 58, 370-391, 1998 (in Japanese).

Geographical Survey Institute of Japan, Crustal movements in the Tokai district, Rep. Cood. Comm. Earthq. Pred., 61, 293-326, 1999 (in Japanese).

Inouchi, N. and T. Hosono, On the yearly change of ground movement detected by precise levelling surveys connecting Kakegawa to 
Omaezaki, Shizuoka prefecture, Japan, J. Geod. Soc. Japan, 33 347-359, 1987

Ishibashi, K., Re-examination of a great earthquake expected in the Tokai district, central Japan-Possibility of the "Suruga bay earthquake", Rep. Cood. Comm. Earthq. Pred., 17, 126-132, 1977 (in Japanese).

Ishibashi, K., Specification of a soon-to-occur seismic faulting in the Tokai district, central Japan, based upon seismotectonics, in Earthquake Prediction, Maurice Ewing Ser., 4, edited by D. W. Simpson and P. G. Richards, pp. 297-332, Am. Geophys. Un. Washington, D.C., 1981.

Ishida, M., Geometry and relative motion of the Philippine Sea plate and Pacific plate beneath the Kanto-Tokai district, Japan, J. Geophys. Res., 97, 489-513, 1992.

Kanamori, H., The energy release in great earthquakes, J. Geophys. Res., 82, 2981-2987, 1977.

Kato, T. and K. Tsumura, Vertical land movement in Japan as deduced from Tidal record (1951-1978), Bull. E.R.I., 54, 559-628, 1979 (in Japanese).

Kotake, Y., T. Kato, S. Miyazaki, and A. Sengoku, Relative motion of the Philippine Sea plate derived from GPS observations and tectonics of the southwestern Japan, Earthquakes, 51, 171-180, 1998 (in Japanese).

Jackson, D. D. and M. Matsu'ura, A Bayesian approach to nonlinear inversion, J. Geophys. Res., 90, 581-591, 1985.

Matsumura, S., Focal zone of a future Tokai earthquake inferred from the seismicity pattern around the plate interface, Tectonophys., 273 271-291, 1997.

Minster, J. B. and T. H. Jordan, Rotation vectors for the Philippine Sea plate and Rivera plates (abstract), EOS trans. Am. Geophys. Un., 60, 958, 1979.

Nishi, S., On the estimation of short-term crustal vertical movements in the vicinity of Omaezaki, J. Geod. Soc. Japan, 31, 212-219, 1985 (in Japanese).

Peterson, E. T. and T. Seno, Factors affecting seismic momemt release rates in subduction zones, J. Geophys. Res., 89, B12, 10233-10248, 1984.

Ruff, L. and H. Kanamori, The rupture process and asperity distribution of three great earthquakes from long-period diffracted $\mathrm{P}$ waves, Phys. Earth Planet. Inter., 31, 202-230, 1983.

Sagiya, T., Crustal deformation cycle and interplate coupling in Shikoku, southwest Japan, Ph.D. Thesis, Fac. of Science, Univ. of Tokyo, 164 pp., 1995

Sagiya, T., Interplate coupling in the Tokai district, central Japan, deduced from continuous GPS data, Geophys. Res. Lett., 26, 2315-
2318, 1999.

Savage, J. C., A dislocation model of strain accumulation and release at a subduction zone, J. Geophys. Res., 88, 4984-4996, 1983.

Scholz, C. H. and T. Kato, The behaviour of a convergent plate boundary: crustal deformation in the south Kanto district, Japan, $J$. Geophys. Res., 83, 783-797, 1978.

Seno, T., The instantaneous rotation vector of the Philippine Sea plate relative to the Eurasian plate, Tectonophys., 42, 209-226, 1977.

Seno, T., S. Stein, and A. E. Gripp, A model for the motion of the Philippine Sea plate consistent with NUVEL-1 and geological data, J. Geophys. Res., 98, 17941-17948, 1993.

Somerville, P., The accommodation of plate collision by Deformation in the Izu block, Japan, Bull. Earthq. Res. Inst., Univ. of Tokyo, 53, 629-648, 1978.

Tajima, M., N. Matsumoto, and M. Kaizu, Relation between seasonal variation of the Omaezaki peninsula and sea level change, J. Geod. Soc. Japan, 30, 107-113, 1984.

Tanaka, M., Correlation between change in elevation of the Omaezaki peninsula and sea level change, Report at the sectional meeting of area of intensified observation in CCEP, 1981.

Tanaka, M. and T. Gomi, Crustal movement observed from horizontal and vertical variations above the subduction zone, J. Geod. Soc. Japan, 35(2), 187-206, 1989.

The Research Group for Active Faults of Japan, Active faults in Japan-sheet maps and inventories, University of Tokyo Press, 437 pp, 1991 (in Japanese).

Tsuboi, C., Investigation on the deformation of the earth's crust found by precise geodetic means, Jap. J. Astron. Geophys., 10, 93-248, 1933

Utsu, T., Space-time pattern of large earthquakes occurring off the pacific coast of the Japanese islands, J. Phys. Earth, 22, 325-342, 1974

Vanicek, P. and E. Krakiwsky, Geodesy, the Concepts, 691 pp., North Holland, 1982.

Yabuki, T. and M. Matsu' ura, Geodetic data inversion using a Bayesian information criterion for spatial distribution of fault slip, Geophys. J. Int., 109, 363-375, 1992.

Yoshioka, S., T. Yabuki, T. Sagiya, T. Tada, and M. Matsu'ura, Interplate coupling and relative plate motion in the Tokai district, central Japan, deduced from geodetic data inversion using ABIC, Geophys. J. Int., 113, 607-621, 1993.

G. El-Fiky (e-mail: el-fiky@eri.u-tokyo.ac.jp) and Teruyuki Kato (e-mail: teru@eri.u-tokyo.ac.jp) 